\title{
Morphological, functional characterization and evaluation of biological value of microencapsulated Aloe vera (L.) Burm. f.
}

\author{
Devina Vaidya, Anuradha Pandit, Anshu Sharma , Manisha Kaushal, Harpreet Kaur Saini, Anupama Anand, Ruchi Sharma \\ and Anil Gupta \\ Department of Food Science and Technology, AICRP on PHET, Dr. Y.S. Parmar University of Horticulture and Forestry, Nauni-173230, Solan, \\ Himachal Pradesh, India

\begin{tabular}{|c|c|}
\hline ifo & Ict \\
\hline $\begin{array}{l}\text { Article history } \\
\text { Received } 15 \text { October } 2021 \\
\text { Revised } 6 \text { December } 2021 \\
\text { Accepted } 7 \text { December } 2021 \\
\text { Published Online } 30 \text { December } 2021\end{array}$ & $\begin{array}{l}\text { Nowadays, encapsulation of herbal extracts has become common due to the improvement in the retention } \\
\text { time of the nutrients present in the food and control release at specific time after consumption of food } \\
\text { in the intestinal gut. The present study was conducted to evaluate the morphological, functional and } \\
\text { biological value of microencapsulated Aloe vera (L.) Brum. f. In order to encapsulate A. vera juice, spray } \\
\text { drying was done along with } 7 \text { per cent carrier material of maltodextrin as per the standard procedure. }\end{array}$ \\
\hline $\begin{array}{l}\text { Keywords } \\
\text { Aloe vera (L.) Brum. f. } \\
\text { Spray drying } \\
\text { Maltodextrin } \\
\text { Quality } \\
\text { Morphology } \\
\text { Diabetes } \\
\text { Treatment }\end{array}$ & $\begin{array}{l}\text { techniques such as scanning electron microscopy, nuclear magnetic resonance spectroscopy and high } \\
\text { performance liquid chromatography. To evaluate the medicinal effects of A. vera, a pre-clinical trial was } \\
\text { conducted to see the effect of encapsulated A. vera powder and A. vera juice on diabetic guinea pigs. } \\
\text { Guinea pigs were induced with type } 2 \text { diabetes by using steptozotocine and further administered with } A \text {. } \\
\text { vera in the form of juice as well as spray dried powder during their treatment. Four hundred milligram of } \\
\text { spray dried A. vera juice powder and five milliliter of A. vera juice showed a prominent effect on } \\
\text { balancing the level of glucose, cholesterol and triglyceride. Henceforth, encapsulated powder of A. vera } \\
\text { can be suggested for the treatment of type } 2 \text { diabetes mellitus. }\end{array}$ \\
\hline
\end{tabular}

\section{Introduction}

The effectiveness of plant based drugs in the traditional medicines has led to their exploration at a high rate as they are comparatively cheaper and have very few side effects (Rathore et al., 2017). Majority of people in developing countries depend upon traditional system of medicines for the primary healthcare. According to World Health Organizaton (WHO), about 80 per cent of the individuals from developed countries prefer using traditional medicines which makes their investigation a priority for better understanding of their properties, efficiency and safety aspects (Yadav and Srivastava, 2014).

In addition, the contribution of Indian indigenous drugs is still of utmost importance besides the rapid progress in scientific technology. Although, many have been replaced by traditional pharmaceutical approaches because of the interest of general public for the use of natural products world-wide. As a result of scientific efforts aimed at improving the understanding of their effect on human physiology, some plants have been thoroughly characterized and their mechanism of action is now well understood. There are numerous medicinal plants identified and used throughout the world for centuries. However, medicinal plants during this scenario face a lot of problems such as over exploitation, adulteration, unhealthy

Corresponding author: Dr. Anshu Sharma

Department of Food Science and Technology, AICRP on PHET, Dr. Y.S. Parmar University of Horticulture and Forestry, Nauni-173230, Solan, Himachal Pradesh, India

E-mail: anshufst1989@gmail.com

Tel.: +91-8219884944

Copyright () 2021 Ukaaz Publications. All rights reserved.

Email: ukaaz@yahoo.com; Website: www.ukaazpublications.com processing, extinction, storage problems, false marketing, etc. (Manoharachary and Nagaraju, 2016). Further, unlimited plants used in pharmacology are yet to be characterized and undergo scientific testing on their proposed efficacy against diseases. Hence, there is a need for scientific validation of the traditional medicinal plant based drugs to increase their usage and establish their efficacy in the modern times.

Diabetes mellitus, a major lifestyle disease is undoubtedly the most challenging public health problem of $21^{\text {st }}$ century which leads to obesity, insulin resistance, glucose intolerance, lipid abnormalities, impaired fasting glucose and impaired glucose tolerance. According to a statistic data, 470 million patients of pre-diabetes are expected by 2030 (Tabak et al., 2012). However, to overcome this problem the benefits of medicinal plants such as A. vera, is quite relevant since ancient times in literature.

A. vera is a medicinal plant with many reputed health benefits and has many references in many cultures: Ancient Egyptians, Greeks, Romans, Indians and Chinese, etc. (Ahlalwat and Khatkar, 2011). $A$. vera based clinical evaluations have revealed that the pharmacologically active ingredients are concentrated in both the gel and rind of its leaves. A. vera is known for their nutraceutical properties including antiviral, antibacterial, laxative, antioxidant, anti-inflammation, anticancerous, antidiabetic, antiallergic, immunostimulation, UV protecting activity, etc. It contains a wide variety of biological compounds in the form of polysaccharides such as mannan, glucogalactomannan, arabinogalactan, xylan, vitamins (A, C, E, $\mathrm{B}_{12}$, folic acid), minerals ( $\mathrm{Ca}, \mathrm{Cu}, \mathrm{Fe}, \mathrm{Mg}, \mathrm{K}, \mathrm{P}, \mathrm{Na}$, $\mathrm{Zn}$ ), enzymes (alkaline phosphatase, amylase, catalase, oxidase, superoxide dismutase) and phenolic compounds such as aloin and 
other derivatives (Ramachandran and Nagrajan, 2014; Sharma et al., 2021).

Due to the high water activity (>0.90) of A. vera and carbohydrate composition, its shelf life period is 3 to 4 days at room temperature, so it is necessary to use a conservation process to preserve most of the active ingredients and increase its life span. The method of preparation often involves some type of processing such as heating, dehydration and grinding. Nevertheless, many aloe products have very little or no active components as a function of inefficient processing practices, necessitating the development of new preservation methods which would increase the shelf life of $A$. vera gel and simultaneously maintaining its high quality. One of the most common technologies for this purpose is encapsulation of compounds by drying. Microencapsulation is one of the techniques used for enhancing the shelf life and stability of food ingredients for over 60 years. It is described as a technique in which a bioactive compound is encapsulated by a biopolymer, so that it is protected from oxygen, light, water or other environmental conditions (Desai and Park, 2005). The main advantage of using this technique is the retention of most of the valuable properties of raw material, e.g., shape, dimensions, appearance, taste, colour, flavour, texture and bioactivity (Ceballos et al., 2012). Moreover, it improves the retention time of the nutrients in the food and allows the control release at specific time during food consumption or in the intestinal gut. Spray drying is a water evaporation technique that uses air hot to stabilize solutions and suspensions in order to produce light powders. It has the capability to be used in high-value commodities because of the advantages it offers over conventional drying procedures in terms of product structure, quality and volatile as well as bioactive ingredient retention (Ishwarya et al., 2015). Therefore, the surface structure and morphology of the prepared dry powders using scanning electron microscopy (SEM) is an ideal way to study the microstructures of prepared products (Deng and Zhao, 2008). Moreover, the sample preparation process does not affect the powder quality, thus SEM can properly show the morphology of powder.

Other advance instrumental techniques named proton nuclear magnetic resonance ${ }^{1} \mathrm{HNMR}$ and high performance liquid chromatography (HPLC) are powerful tools to access the quality of encapsulated powders in order to identify and monitor the presence of the medicinal and antinutritional components as they are safe, fast and sensitive to analyse varieties of functional and biological compounds with high accuracy (Farsadegh and JafarizadehMalmiri, 2019). Further, preclinical studies have suggested that $A$. vera gel may act as a safe antihyperglycemic and antihyper cholesterolemic agent for type 2 diabetic patients without any significant effects on other normal blood lipid levels or liver/kidney function (Huseini et al., 2012). Jain et al. (2011) found that this gel has strong antidiabetic and cardioprotective effects too, as it greatly decreases oxidative stress and enhances antioxidant capacity in streptozotocin-induced diabetic rats. The oral administration of processed A. vera gel reduced plasma lipid levels and hepatic triacylglyceride concentration in diet induced obesity mice. Henceforth, the study was designed to study the morphological characteristics and biological value of microencapsulated A. vera.

\section{Materials and Methods}

\subsection{Extraction of $A$. vera gel and spray drying}

A. vera leaves were procured from botanical garden of Department of Medicinal and Aromatic Plants, College of Forestry, Dr. Y.S. Parmar University of Horticulture and Forestry, Nauni, Solan (Figure 1). The harvested leaves were brought to the laboratory and mechanical method was used for the extraction of gel. The machine was procured from AICRP on PHET, Udaipur, Rajasthan, India. A mobile spray dryer in parallel flow (Labultima LU 222 Advance Spray Drier) equipped with rotary atomizer was used to dry the solution of A. vera mucilage. Seven per cent maltodextrin as carrier material with A. vera juice at inlet temperature of $150^{\circ} \mathrm{C}$ in the drying chamber using a peristaltic pump. The flow rate of the atomizing air was $600 \mathrm{ml} / \mathrm{min}$ and the aspirator rate was 60 per cent of 100 per cent $(0.0149 \mathrm{~kg} / \mathrm{s})$. The testing was carried out under invariable process conditions. Further, the prepared dried product was vacuum sealed in amber shade coloured glass jars.

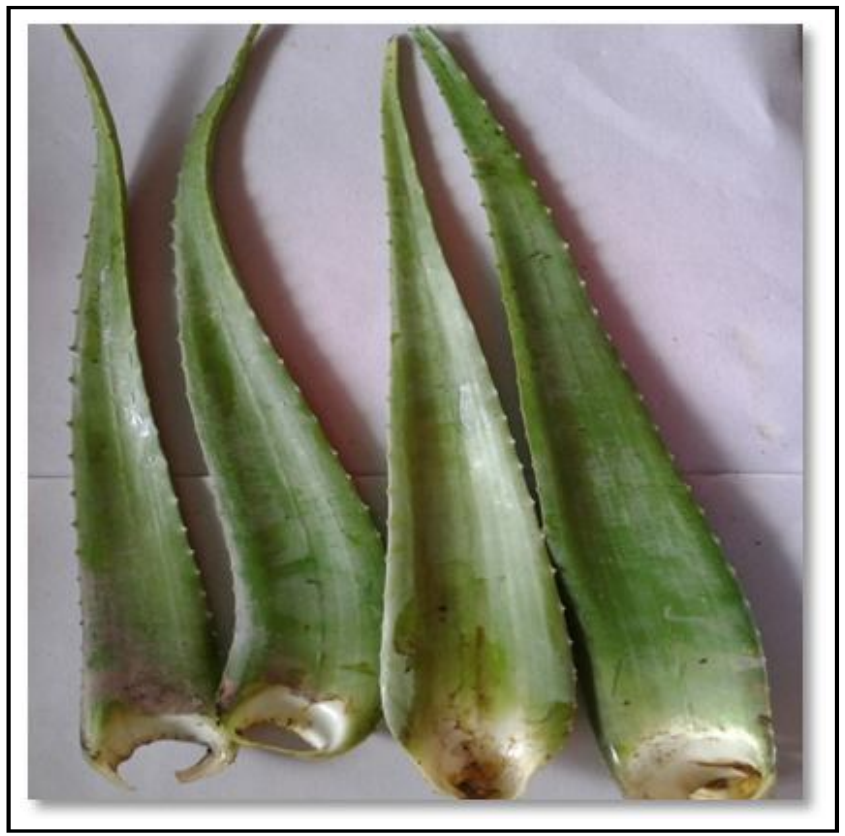

Figure 1: Fresh A. vera leaves.

\subsection{Observations recorded}

Spray dried A. vera powder was taken for various experiments. Following parameters were estimated during the studies.

\subsubsection{Morphology of A. vera powder}

The powder's morphology was assessed using an EmCraft (Korea): Table-top scanning electron microscope (SEM Cube-1000). Dehydration of samples was accomplished using critical point drying equipment. The powder was fixed in an aluminum plate, using an electrically conductive tap and a coating of gold at 10 mbar for $90 \mathrm{sec}$ was applied. The microscope was operated at $5 \mathrm{kV}$ and at different levels of magnification, viz., 500x, 1000x, 1500x with secondary electron mode.

\subsubsection{Quantification of aloin by HPLC}

For quantification of aloin, solution of different concentrations, i.e., 50, 100 and $125 \mathrm{ppm}$ of pure aloin was made in HPLC grade 
methanol. $20 \mu \mathrm{l}$ of each concentration of aloin compound was injected in HPLC and area under curve (AUC) was recorded at 290 $\mathrm{nm}$ wavelength. Standard curve was prepared for AUC and concentrations for each compound. Waters HPLC unit with waters HPLC pump 515 and dual $\ddot{e}$ absorbance detector 2487 was used in which methanol and water (50:50) were mobile phase. Flow rate was maintained @ $100 \mathrm{ml} / \mathrm{min}$. Column used was Sunfire ${ }^{\mathrm{TM}} \mathrm{C}-18$ $(4.6 \times 250 \mathrm{~mm}, 5 \mu \mathrm{m})$.

\subsection{3 ${ }^{1}$ HNMR spectroscopy}

The sample $(2 \mathrm{mg})$ was dissolved in deuterium oxide $(0.7 \mathrm{ml})$ and transferred in Schott Economic $5 \mathrm{~mm}$ NMR tubes prior to analysis. ${ }^{1}$ HNMR spectra were recorded on Bruker AC NMR-Spectrometer, Switzerland (Bozzi et al., 2007).

\subsection{Biological activity of $A$. vera juice and spray dried powder}

Hypoglycaemic and hypolipedemic efficacy of spray dried A. vera powder and juice were observed by conducting a preclinical trial on guinea pigs. Preclinical study was undertaken as per the international standards of animal care in the Central Drug Laboratory (CDL), National Accreditation Board for Testing and Calibration Laboratories (NABL) accreditated laboratory (ISO/IEC 17025:2005) in the field of biological and chemical testing of Central Research Insititute (CRI), Kasauli, Himachal Pradesh, India. Guinea pigs were grouped into 9 groups comprising of 8 pigs each. For all of the groups, the average weight was adjusted to be the same. The $A$. vera juice @ $2.5 \mathrm{ml}$ and $5 \mathrm{ml} / \mathrm{kg}$ was given to the animals and spray dried powder@200 mg and 400 mg/kg was administered. The powder was dissolved in phosphate buffer just before administration. The dosing schedule used was once per day along with regular diet.

\subsubsection{Induction of experimental diabetes}

After fasting, diabetes was induced by intraperitoneal injection of single dose streptozotocin (STZ) freshly dissolved in $0.1 \mathrm{M}$ cold sodium citrate buffer ( $\mathrm{pH} 4.5$ ) at a dose of $100 \mathrm{mg} / \mathrm{kg}$ body weight. After injection, they had a free access to food and water. They were given 5 per cent glucose solution to drink overnight to counter hypoglycemic shock. Body weight and biochemical estimations such as plasma glucose (PGL), triglycerides (PTG), total cholesterol (PTC) and insulin (PI)) were carried out just before and after 7 days of the STZ injection. Detail of treatments is as $\mathrm{T}_{1}$ : normal control, $\mathrm{T}_{2}$ : normal control + juice, $\mathrm{T}_{3}$ : diabetic control, $\mathrm{T}_{4}$ : diabetic +2.5 $\mathrm{ml}$ juice, $\mathrm{T}_{5}$ : diabetic $+5 \mathrm{ml}$ juice, $\mathrm{T}_{6}:$ diabetic $+200 \mathrm{mg}$ microencapsulated A.vera, $\mathrm{T}_{7}$ : diabetic $+400 \mathrm{mg}$ microencapsulated A.vera, $\mathrm{T}_{8}$ : diabetic + metformin and $\mathrm{T}_{9}$ : normal control + maltodextrin

\subsubsection{Housing of animals}

The animals were housed in standard cages with bedding of hard wood shavings. The hard wood shavings were added to the cages for environmental enrichment. The guinea pigs were kept in a controlled environment with a room temperature of $22 \pm 1^{\circ} \mathrm{C}$ and $12 \mathrm{~h}$ light-dark cycle. The guinea pigs were allowed to adapt to the housing conditions and interventions (feeding and weighing) three days before the commencement of the experimental trials. Total of 72 guinea pigs having a blood glucose level of $>180 \mathrm{mg} / \mathrm{dl}$ were chosen and divided into nine groups, each with eight individuals.

\subsubsection{Administration of juice and microencapsulated powder}

A. vera was orally administered @ 2.5 and $5 \mathrm{ml}$ juice and 200 and $400 \mathrm{mg}$ powder/kg body weight for 15 days daily along with regular diet.

\subsubsection{Blood sampling and plasma processing}

After the animals were anesthetized, blood samples were collected via cardiac puncture using $21 \mathrm{G}$ needles and $10 \mathrm{ml}$ syringes. Half of the blood $(5 \mathrm{ml})$ was transferred into plain blood tubes (Geiner Bio-one $\mathrm{GmbH}$, Austria) and the rest into EDTA tubes (Novo Nordisk Company, Johannesburg, South Africa). The blood samples were spun for $10 \mathrm{~min}$ at $5000 \mathrm{x} \mathrm{g}$ at $10^{\circ} \mathrm{C}$ in a centrifuge. The plasma and serum were collected and then stored at minus $20^{\circ} \mathrm{C}$ for the analysis of plasma glucose, insulin, cholesterol, triglycerides, blood nitrogen urea and creatinine.

\section{Results}

\subsection{Morphology and microstructure}

Morphology of powder is reported in terms of size and shape of particles along with internal structures and surface characteristic. The image analysis (500x, 1000x and 1500x) in Figure 2 (a), (b) and (c) shows spherical particles with uniform appearance. Droplets were dried in symmetry and impart spherical shape to the particles. These morphological characteristics showed by organic materials and stabilizers for carbohydrate-based chemistries.

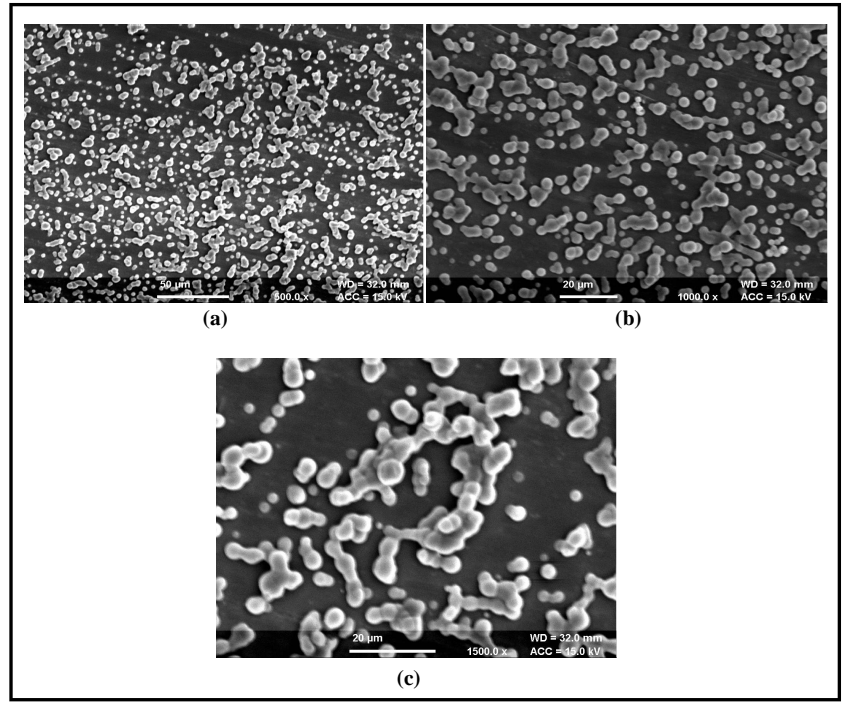

Figure 2: Cryo-SEM micrograph of microencapsulated A. vera juice powder (a) 500x (b) 1000x (c) 1500x.

3.2 Quantification of aloin in microencapsulated $A$. vera

The aloin content was estimated using HPLC (Waters HPLC Unit) which was found to be 0.0033 per cent $(0.0000033 \mathrm{ppm})$ in spray dried A. vera powder which is under permissible limits of aloin in food products (i.e.,10 ppm).

\section{$3.3{ }^{1} \mathrm{HNMR}$}

The ${ }^{1}$ HNMR assignment of microencapsulated $A$. vera revealed signals from all protons in the sample simultaneously. Acemannan acetylation fingerprint distribution of methyl resonances was 
observed between 2.0-2.2 ppm. Maltodextrin was also detected and quantified by ${ }^{1} \mathrm{HNMR}$. Microencapsulated A. vera contained maltodextrins peaks at 5.4 and in the $3.5-4.0 \mathrm{ppm}$ region which was used to quantify the presence of maltodextrin.

\subsection{Biological value of $A$. vera juice and microencapsulated $A$. vera}

Diabetes was induced in experimental guinea pig by injecting calculated dose of the chemical streptozotocin. Group $T_{1}$ fed normal diet and served as normal control, $\mathrm{T}_{2}$ also fed with normal diet but also had A.vera juice @ $2.5 \mathrm{ml}$, group $\mathrm{T}_{3}$ animals were induced with diabetes and served as diabetic control, group $\mathrm{T}_{4} \mathrm{~T}_{5}, \mathrm{~T}_{6}$ and $\mathrm{T}_{7}$ were administrated with A.vera juice and microencapsulated powder @ $2.5 \mathrm{ml}, 5 \mathrm{ml}, 200 \mathrm{mg}$ to $400 \mathrm{mg}$, respectively. Group $\mathrm{T}_{8}$ was given standard drug metformin for diabetes and group $\mathrm{T}_{9}$ was subjected to maltodextrin to see its effect on the animals.

\subsubsection{Body weight}

Table 1 presents the body weight and blood glucose level of healthy guinea pigs. The range of glucose level for healthy guinea pig was varied from 70 to $89.17 \mathrm{mg} / \mathrm{dl}$ while body weight of most of the guinea pigs was 257 to $300 \mathrm{~g}$. Table 2 illustrates the effect of treatments on the body weight of experimental animals. A. vera fed guinea pig had non-significant increase in body weight as compared to normal control while diabetic control animals had significant decrease in the body weight, i.e., $257 \pm 1.452$ to $237 \pm 1.763 \mathrm{~g}$.

Table 1: Body weight and blood glucose level of healthy guinea pigs

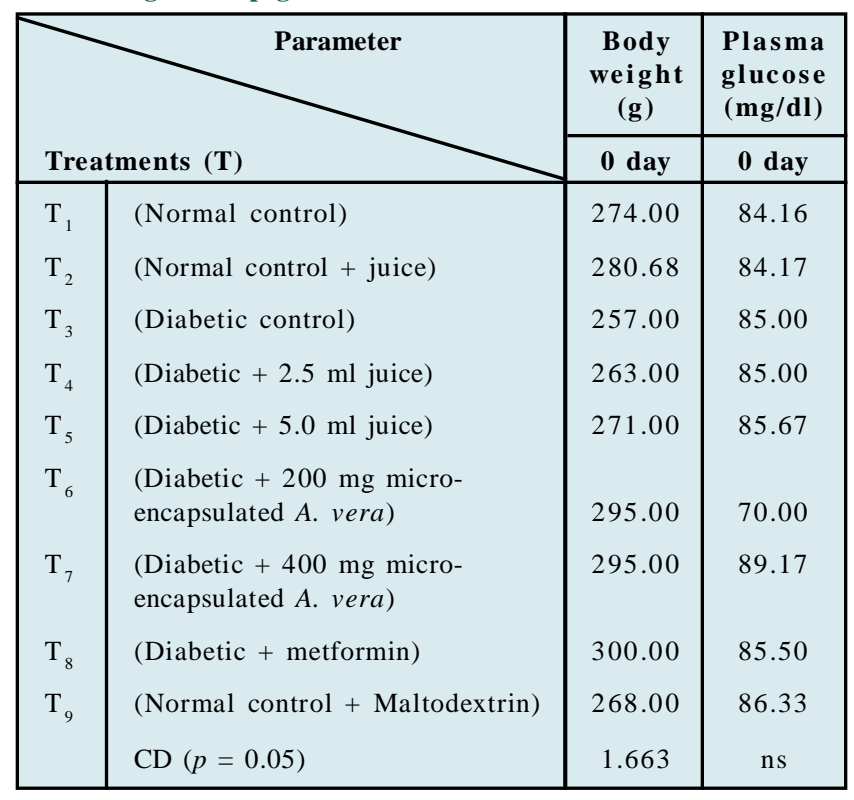

\subsubsection{Blood glucose}

The mean blood glucose level of diabetic control guinea pig was $187.83 \pm 9.15 \mathrm{mg} / \mathrm{dl}$, while that of regular diet fed guinea pig was $89.50 \pm 8.46 \mathrm{mg} / \mathrm{dl}$ (Figure 3 ). In animals administrated with streptozotocin $(50 \mathrm{mg} / \mathrm{kg}$ i.p.), a significant increase in plasma glucose level was observed on $7^{\text {th }}$ and $15^{\text {th }}$ day when compared with normal guinea pig $\left(\mathrm{T}_{1}\right)$. Group $8\left(\mathrm{~T}_{8}\right)$ received metformin $(60 \mu \mathrm{g} / \mathrm{kg}$ body weight) showed decrease in serum glucose level when compared with diabetic control guinea pig $\left(\mathrm{T}_{3}\right)$. After the oral administration of juice and powder of A.vera in diabetic guinea pig, a significant reduction in blood glucose level was observed on the $15^{\text {th }}$ day compared with diabetic control guinea pig $\left(\mathrm{T}_{3}\right)$. The maximum effect was observed in $\mathrm{T}_{5}(5 \mathrm{ml} / \mathrm{kg}$ body weight A.vera juice) and $400 \mathrm{mg}$ microencapsulated $A$. vera $\left(\mathrm{T}_{7}\right)$. There was observed negligible difference in food intake over the treatment period in treated and untreated guinea pigs.

Table 2: Effect of A.vera juice and microencapsulated powder on body weight of STZ induced diabetic guinea pigs

\begin{tabular}{|c|c|c|c|c|}
\hline \multirow{2}{*}{ Parameters } & \multicolumn{2}{|c|}{ Body weight (g) } & $\begin{array}{c}\text { 2-tailed } \\
\text { probability }\end{array}$ & $\begin{array}{c}\text { Statistical } \\
\text { results }\end{array}$ \\
\cline { 2 - 4 } & $\begin{array}{c}\text { A } \\
\text { (Mean } \\
\pm \text { SEM) }\end{array}$ & $\begin{array}{c}\text { B } \\
\text { (Mean } \\
\pm \text { SEM) }\end{array}$ & & \\
\hline $\mathrm{T}_{1}$ & $274 \pm 0.577$ & $295 \pm 0.577$ & 0.003 & $\mathrm{~s}$ \\
$\mathrm{~T}_{2}$ & $281 \pm 0.567$ & $285 \pm 2.857$ & 0.270 & $\mathrm{~ns}$ \\
$\mathrm{~T}_{3}$ & $257 \pm 1.452$ & $237 \pm 1.763$ & 0.022 & $\mathrm{~s}$ \\
$\mathrm{~T}_{4}$ & $263 \pm 0.587$ & $265 \pm 2.886$ & 0.597 & $\mathrm{~ns}$ \\
$\mathrm{~T}_{5}$ & $268 \pm 0.577$ & $271 \pm 1.452$ & 0.093 & $\mathrm{~ns}$ \\
$\mathrm{~T}_{6}$ & $284 \pm 2.333$ & $295 \pm 0578$ & 0.040 & $\mathrm{~s}$ \\
$\mathrm{~T}_{7}$ & $292 \pm 1.453$ & $298 \pm 1.855$ & 0.089 & $\mathrm{~ns}$ \\
$\mathrm{~T}_{8}$ & $293 \pm 0.882$ & $298 \pm 1.855$ & 0.047 & $\mathrm{~s}$ \\
$\mathrm{~T}_{9}$ & $300 \pm 0.578$ & $309 \pm 0.577$ & 0.012 & $\mathrm{~s}$ \\
\hline
\end{tabular}

$\mathrm{T}_{1}$ : Normal control, $\mathrm{T}_{2}$ : Normal control + juice, $\mathrm{T}_{3}$ : Diabetic control, $\mathrm{T}_{4}$ : Diabetic $+2.5 \mathrm{ml}$ juice, $\mathrm{T}_{5}$ : Diabetic $+5.0 \mathrm{ml}$ juice, $\mathrm{T}_{6}$ : Diabetic + $200 \mathrm{mg}$ microencapsulated A. vera, $\mathrm{T}_{7}$ : Diabetic $+400 \mathrm{mg}$ microen capsulated A. vera, $\mathrm{T}_{8}$ : Diabetic + metformin, $\mathrm{T}_{9}$ : Normal control + maltodextrin

A- After 7 days of induction of streptozotocin

B- After 15 days of induction of streptozotocin

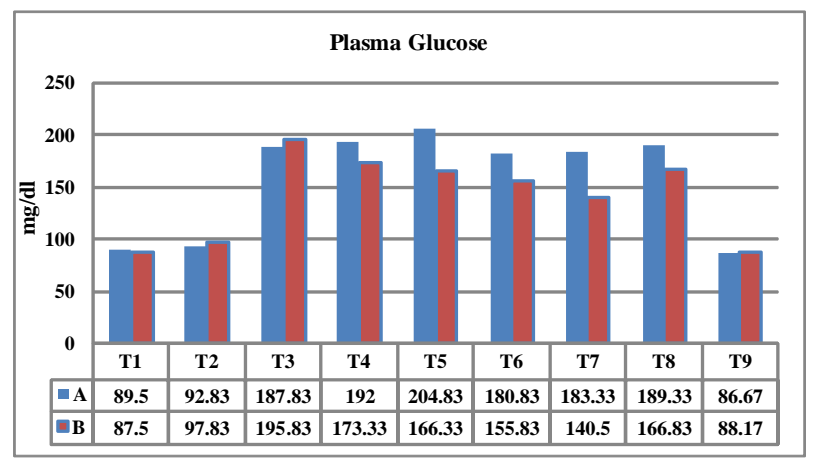

A-After 7 days of induction of streptozotocin

B- After 15 days of induction of streptozotocin

Figure 3: Effect of A.vera juice and microencapsulated powder on plasma glucose of STZ induced diabetic guinea pigs.

\subsubsection{Insulin levels}

The insulin levels of guinea pigs were measured after the various treatments are presented in Figure 4. The insulin level of diabetic guinea pig was significantly higher than those of normal healthy 
animals. Aloe juice ( $5 \mathrm{ml}$ ) and microencapsulated A. vera $(400 \mathrm{mg})$ fed to guinea pig showed a significant effect on the insulin level compared to the diabetic control animals.

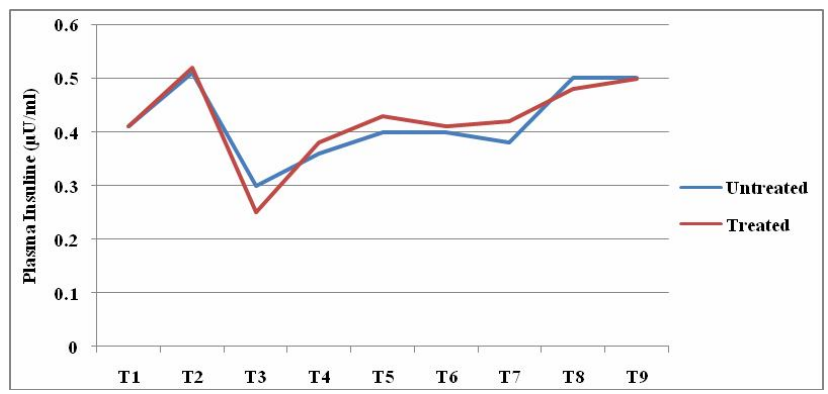

Figure 4: Effect of A.vera juice and microencapsulated powder on insulin of STZ induced guinea pigs.

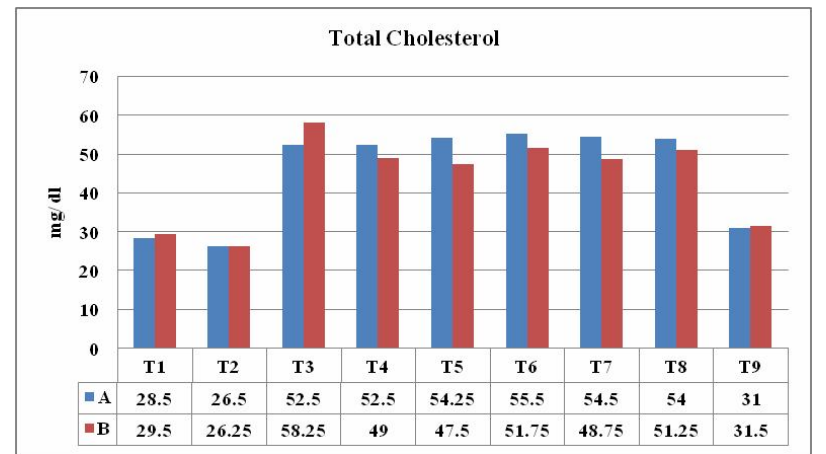

A-After 7 days of induction of streptozotocin

B-After 15 days of induction of streptozotocin

Figure 5: Effect of A.vera juice and microencapsulated powder on total cholesterol of STZ induced diabetic guinea pigs.

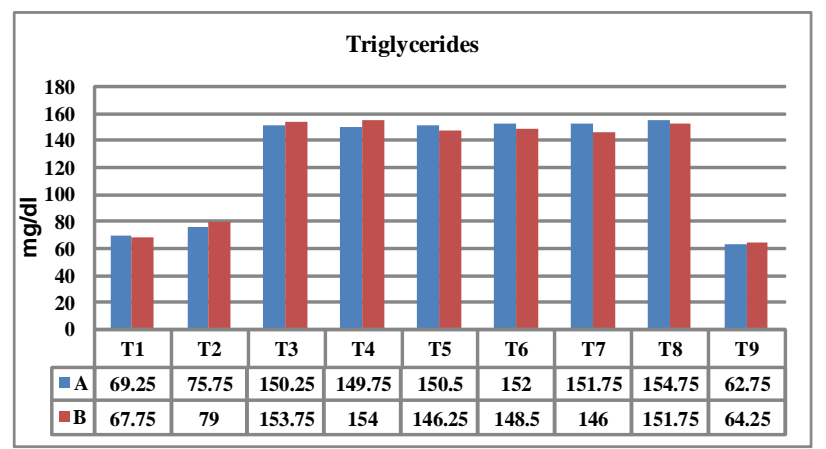

A-After 7 days of induction of streptozotocin B-After 15 days of induction of streptozotocin

Figure 6: Effect of A.vera juice and microencapsulated powder on triglycerides of streptozotocin induced diabetic guinea pigs.

\subsubsection{Blood lipid profile}

\subsubsection{Total cholesterol}

The mean serum level of total blood cholesterol of the experimental group data is presented in the Figure 5. Total cholesterol levels were significantly higher in diabetic induced guinea pigs than those of normal guinea pig. After 15 days treatment of $A$. vera juice and powder, cholesterol level was decreased significantly and dose dependently. A. vera juice $(5 \mathrm{ml})$ and microencasulated powder (400 mg) showed significant effect on cholesterol level (47.50 and $48.75 \mathrm{mg} / \mathrm{dl})$.

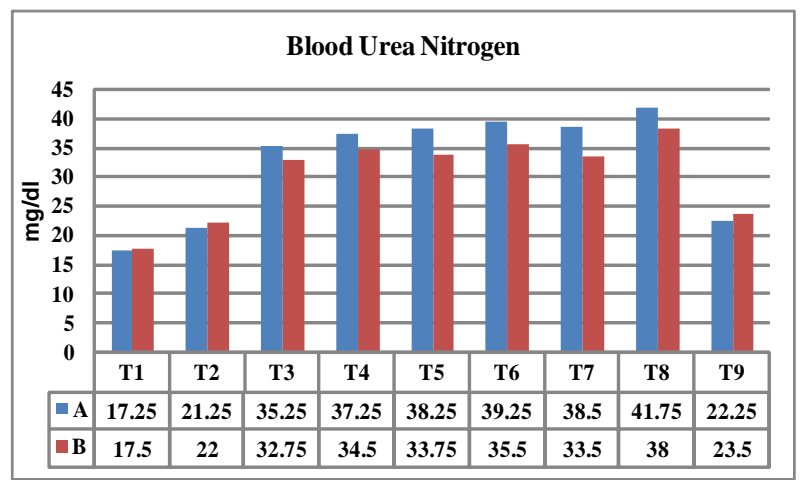

A-After 7 days of induction of streptozotocin B-After 15 days of induction of streptozotocin

Figure 7: Effect of A.vera juice and microencapsulated powder on blood urea nitrogen of STZ induced diabetic guinea pigs.

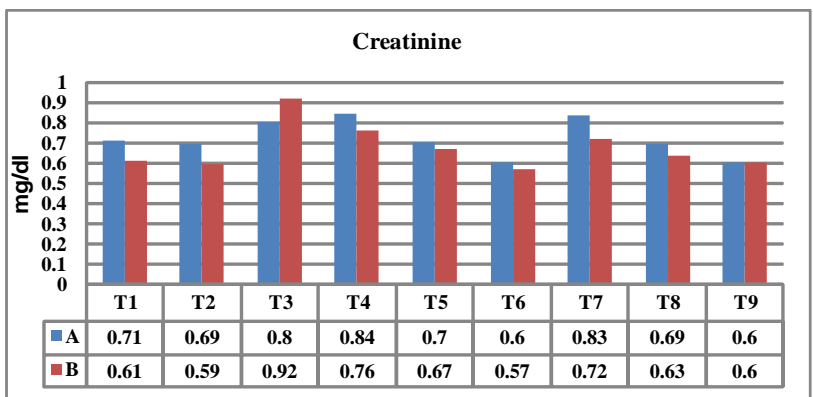

A-After 7 days of induction of streptozotocin B-After 15 days of induction of streptozotocin

Figure 8: Effect of A.vera juice and microencapsulated powder on creatinine of STZ induced diabetic guinea pigs.

\subsubsection{Triglycerides}

Figure 6 reveals the effect of $A$. vera juice and powder on triglycerides level of the blood profile of the guinea pig. The results show that the there is significant decrease $(p<0.005)$ in the triglycerides of guinea pig with $5 \mathrm{ml} \mathrm{A}$. vera juice $(p=0.037)$ and $400 \mathrm{mg}(p=0.025)$ of powdered $A$. vera followed by $2.5 \mathrm{ml}$ juice and $200 \mathrm{mg}$ dose when compared to control animals.

\subsubsection{Effect on urea and creatinine level}

These findings reveal that there is a strong relationship of blood sugar level with urea level. As an increase in blood sugar and urea level was detected. The study shows a significant decrease in blood nitrogen urea in treated guinea pigs. $5 \mathrm{ml}$ of juice ( 38.25 to 33.75 $\mathrm{mg} / \mathrm{dl}$ ) and $400 \mathrm{mg}$ of microencapsulated A. vera (38.5 to $33.5 \mathrm{mg} /$ dl) showed the significant effect on blood nitrogen of guinea pig (Figure 7). But, non-significant results were observed for creatinine level of animals (Figure 8). 


\section{Discussion}

4.1 Morphological properties of microencapsulated $A$. vera gel

Phytosterols from A. vera, are frequently unstable across a wide variety of processing or storage conditions, which is one of their major downsides for its ultimate application (Khoshnoudi et al., 2020). To overcome this drawback, spray dried $A$. vera juice was microencapsulated to offer the required protection to sensitive bioactive components against oxidation and degradation during various stages of utilization. Spray drying of $A$. vera juice resulted in spherical particles with uniform appearance, which suggested that the droplets were dried symmetrically. These morphological characteristics are usually showed by organic materials and stabilizers composed of carbohydrate-based chemistries. Presence of carbohydrates results in formation of agglomerates caused by Van der Waals and electro-static interactions occurring in the molecules (Cervantes-Martínez et al., 2014).

\subsection{Quantification of aloin content}

Aloin is a secondary metabolite present specifically in A. vera plant, having anti-inflammatory, lipid lowering, antimicrobial, laxative and antioxidant properties. Besides its therapeutic effects, if taken in excess, behaves as toxin in form of mild gastrointestinal irritant or may cause abdominal cramps and diarrhea (Logaranjan $e t$ al., 2013). Aloin content of studied samples was within the safe limits as specified by International Aloe Science Council (IASC), viz., preferably less than $10 \mathrm{ppm}$ for A. vera products with the exception of alcoholic beverages (50 ppm).

\section{$4.3{ }^{1}$ HNMR spectra of $A$. vera gel powder}

${ }^{1} \mathrm{HNMR}$ was found to be an essential tool to access the quality of A. vera gel preparations, monitoring the presence of the acemannan, a natural polysaccharide of $A$. vera gel. Acemannan is bioactive polysaccharide showing immunoregulatory, anticancer, antioxidant, and intestinal health enhancement properties (Liu et al., 2019).

\subsection{Biological activity of $A$. vera juice and microencapsulated powder}

In order to determine the antidiabetic and antihyperlipidaemic potential of $A$. vera gel, a trial was conducted to understand the effect of of $A$. vera juice and microencapsulated $A$. vera powder on blood glucose level of the guinea pigs.

\subsubsection{Effect on body weight and blood plasma levels}

It was observed that there was a significant decrease in body weight of diabetic test subjects, attributed to incapability to use carbohydrates and a non-significant increase in non-diabetic subjects. Nwajo (2006) found that there was slight increase in the body weight of rats as compared to the normal healthy rats. While, Ramachandraiahgari et al. (2012) observed that with the dose of $300 \mathrm{mg}$ of $A$. vera extract to rat, there was a significant reduction in body weight of diabetic rats when compared to normal control guinea pigs. The reduction in body weight was attributed to presence of aloe-sterol that might act on liver to motivate energy expenditure as fatty acid oxidation and contributed to decrease in body weight.
Induction of diabetes by administration streptozotocin $(50 \mathrm{mg} / \mathrm{kg})$, significantly increased plasma glucose level of guinea pigs. After the oral administration of juice and powder of A. vera in diabetic guinea pig, there was a significant reduction in blood glucose level. This was most likely due to some phytosterols, polysaccharides or elements such as zinc, chromium, magnesium and manganese present in A. vera which control the diabetes by improving the efficacy of insulin or due to its ability to stimulate insulin secretion from the remnant and/or regenerated $\alpha$-cells (Rajsekaran et al., 2006). Results could be confirmed by findings of Choudhary et al. (2014), where a significant reduction in post prandial blood glucose was reported by treatment with $A$. vera gel powder (100 and $200 \mathrm{mg}$ ).

\subsubsection{Effect on insulin levels}

The insulin level of diabetic guinea pig was significantly higher than those of normal healthy animals. A. vera juice $(5 \mathrm{ml})$ microencapsulated powder $(400 \mathrm{mg})$ fed to guinea pig shows significant effect on the insulin level compared to the diabetic control animals. Kim et al. (2009) suggested that $A$. vera can increase insulin sensitivity in the cells as well as reduce the level of blood glucose and insulin in serum. Antidiabetic effects of A. vera are attributed to its ability to improve insulin secretion along with improved pancreatic $\alpha$-cell function as indicated by study of Noor et al. (2017).

\subsubsection{Effect on blood lipid profile}

Initially, total cholesterol levels of diabetes induced guinea pig were significantly higher than those of normal guinea pigs. After 15 days treatment of $A$. vera juice and powder, cholesterol level decreased significantly and dose dependently. Cholesterol lowering effect of A. vera could be due to its ability to reduce the level of lipids in the blood by strengthening the sensitivity of cells to insulin which leads to the contraction of free fatty acids released from fat tissue to the blood (Amber et al., 2020). In addition to this, certain phytosterols and polysaccharides specifically, acemannan can modify blood cholesterol by regulating fat metabolism in the liver. Results could be confirmed by studies conducted by Misawa et al. (2012), illustrating the effect of two phytosterols, lophenol and cycloartenol, isolated from A. vera, in reducing serum triglycerides, non-esterified fatty acids and total cholesterol.

Triglycerides (TG) are another type of fat that get carried in the blood by very low density lipoproteins. Joshi and Gajraj (2006) observed that the use of $A$. vera extract as much as $200 \mathrm{mg} / \mathrm{kg}$ on a daily basis for as long as 100 days can significantly reduce the level of cholesterol, triglycerides, free fatty acids and phospholipids in mice. Beta-sitosterol chain present in A. vera could be major contributing factor to reduction of total cholesterol, LDL cholesterol and triglycerides because of its ability to inhibit fat absorption in body, thus, supporting the decrease in triglyceride levels of guinea pigs treated with $A$. vera juice and microencapsulates in the current study.

\subsubsection{Effect on urea and creatinine level}

Blood urea nitrogen or BUN test measures the amount of urea nitrogen in blood, while creatinine tests analyze impairment of renal functions by measuring the amount of creatinine phosphate in blood (Pandya et al., 2016). Treatment of guinea pigs with A. vera significantly decreased their blood urea levels, while non- 
significantly affecting the serum creatinine levels. Findings were in line with observations of Bolkent et al. (2004), however, there were contradiction with findings of Saka et al. (2012), where a decrease in serum sodium and potassium was reported, while the levels of urea, bicarbonate and creatinine increased considerably. Their study provides evidence of cytotoxic effects of $A$. vera, which may promote nephrotoxicity and renal function impairment.

\section{Conclusion}

The study concludes that $5 \mathrm{ml}$ of $A$. vera juice and $400 \mathrm{mg}$ of microencapsulated $A$. vera had significant positive effect on triglycerides and blood glucose level of guinea pigs and can be used by the type 2 diabetic patients for treatment. A. vera juice was successfully microencapsulated using spray drying method. Morphologically, the microcapsules possessed uniform appearance as characterized by SEM images. The aloin content determined by HPLC was under permissible limits (below $10 \mathrm{ppm}$ ) and was rendered safe for human consumption. ${ }^{1}$ HNMR spectroscopy revealed the presence of the most significant biological polysaccharide called acemannans. Therefore, microencapsulated A.vera can be used to lower the type 2 diabetes and improve the lipid profile in body because of presence of various important functional components.

\section{Conflict of interest}

The authors declare no conflicts of interest relevant to this article.

\section{References}

Ahlawat, K.S. and Khatkar, B.S. (2011). Processing, food applications and safety of Aloe vera products: A review. Journal of Food Science and Technology, 48:525-533.

Amber, K.; Nofel, R.; Ghanem, R.; Sayed, S.; Farag, S.A.; Shukry, M. and Dawood, M. A. (2020). Enhancing the growth rate, biochemical blood indices, and antioxidative capacity of broilers by including Aloe vera gel in drinking water. Frontiers in Veterinary Science, 7:213-230.

Bolkent, S.; Akev, N.; Ozsoy, N.; Sengezer-Inceli, M.; Can, A.; Okyar, A. and Yanardag, R. (2004). Effect of Aloe vera (L.) Burm. fil. leaf gel and pulp extracts on kidney in type-II diabetic rat models. Indian Journal of Experimental Biology, 42:48-52.

Bozzi, A.; Perrin, C.; Austin, S. and Vera, F.A. (2007). Quality and authenticity of commercial A.vera powders. Food Chemistry, 103:22-30.

Ceballos, A.M.; Giraldo, G.I. and Orrego, C.E. (2012). Effect of freezing rate on quality parameters of freeze dried soursop fruit pulp. Journal of Food Engineering, 111:360-365.

Cervantes-Martinez, C.V.; Medina-Torres, L.; Gonzalez-Laredo, R.F.; Calderas, F.; Sanchez-Olivares, G.; Herrera-Valencia, E.E.; Gallegos-Infante, J.A.; Rocha-Guzman. and Rodriguez-Ramirez, J. (2014). Study of spray drying of the A.vera mucilage as a function of its rheological properties. LWT-Food Science and Technology, 55:426-435

Choudhary, M.; Kochhar, A. and Sangha, J. (2014). Hypoglycemic and hypolipidemic effect of A.vera L. in non-insulin dependent diabetics. Journal of Food Science and Technology, 51:90-96.

Deng, Y. and Zhao, Y.Y. (2008). Effect of pulsed vacuum and ultrasound osmopretreatments on glass transition temperature, texture, microstructure and calcium penetration of dried apples (Fuji).
LWT-Food Science and Technology, 41:1575-1585

Desai, K.G.H. and Park, H.J. (2005). Recent developments in microencapsulation of food ingredients. Drying Technology, 23:13611394.

Fardsadegh, B. and Jafarizadeh-Malmiri, H. (2019). Aloe vera leaf extract mediated green synthesis of selenium nanoparticles and assessment of their in vitro antimicrobial activity against spoilage fungi and pathogenic bacteria strains. Green Processing and Synthesis, 8:399407.

Huseini, H.F.; Kianbakht, S.; Hajiaghaee, R.; Afkhami Ardekani, M.; Bonakdaran, A. and Hashem Dabaghian, F. (2012). A.vera leaf gel in treatment of advanced type 2 diabete mellitus needing insulin therapy:A randomized double-blind placebo-controlled clinical trial. Journal of Medicinal Plants, 11:1-9.

Ishwarya, S.P.; Anandharamakrishnan, C. and Stapley, A.G. (2015). Sprayfreeze-drying: A novel process for the drying of foods and bioproducts. Trends in Food Science and Technology, 41:161-181.

Jain, P.; Chouhan, P. and Shukla, R.N. (2011). Chemical composition of anticancerous component (acemannan and emodin) from Aloe vera and dehydration effect of Aloe at different temperature. An International Journal of Chemistry, 2:147-157.

Joshi, S.C. and Gajraj, A. (2006). Induction of hypocholesterolemia associated with testicular dysfunction by Aloe barbedensis in Albino rats. Pharmacologyonline, 3:1-8

Khoshnoudi-Nia, S.; Sharif, N. and Jafari, S.M. (2020). Loading of phenolic compounds into electrospun nanofibers and electrosprayed nanoparticles. Trends in Food Science and Technology, 95:59-74.

Kim, K.; Kim, H.; Kwon, J.; Lee, S.; Kong, H. and Im, S.A. (2009). Hypoglycemic and hypolipidemic effects of processed Aloe vera gel in a mouse model of non-insulin-dependent diabetes mellitus. Phytomedicine, 16:856-863.

Liu, C.; Cui, Y.; Pi, F.; Cheng, Y.; Guo, Y. and Qian, H. (2019). Extraction, purification, structural characteristics, biological activities and pharmacological applications of acemannan, a polysaccharide from Aloe vera: A review. Molecules, 24:1554.

Logaranjan, K.; Devasena, T. and Pandian, K. (2013). Quantitative detection of aloin and related compounds present in herbal products and Aloe vera plant extract using HPLC method. American Journal of Analytical Chemistry, 4:600-605.

Manoharachary, C. and Nagaraju, D. (2016). Medicinal plants for human health and welfare. Anna. of Phytomedicine., 5:24-34.

Misawa, E.; Tanaka, M.; Nomaguchi, K.; Nabeshima, K.; Yamada, M.; Toida, T. and Iwatsuki, K. (2012). Oral ingestion of Aloe vera phytosterols alters hepatic gene expression profiles and ameliorates obesityassociated metabolic disorders in Zucker diabetic fatty rats. Journal of Agricultural and Food Chemistry, 60:2799-2806.

Noor, A.; Gunasekaran, S. and Vijayalakshmi, M.A. (2017). Improvement of insulin secretion and pancreatic $\alpha$-cell function in streptozotocininduced diabetic rats treated with Aloe vera extract. Pharmacognosy Research, 9(Suppl 1):S99.

Nwajo, H.U. (2006). Antioxidant activity of the exudates from Aloe barbadensis leaves in diabetic rats. Biokemistri,18:77-81.

Pandya, D.; Nagrajappa, A.K. and Ravi, K.S. (2016). Assessment and correlation of urea and creatinine levels in saliva and serum of patients with chronic kidney disease, diabetes and hypertension- 
a research study. Journal of Clinical and Diagnostic Research: JCDR, 10, ZC58.

Rajasekaran, S.; Ravi, K.; Sivagnanam, K. and Subramanian, S. (2006). Beneficial effects of Aloe vera leaf gel extract on lipid profile status in rats with streptozotocin diabetes. Clinical and Experimental Pharmacology and Physiology, 33:232-237.

Ramachandraiahgari, R.M.Y.; Somesula, S.R.; Adi, P.J.; Mannur, I.S.; Enamala, M. and Matcha, B. (2012). Protective role of ethanolic extract of Aloe vera antioxidant properties on liver and kidney of streptozotocin-induced diabetic rats. Digest Journal of Nanomaterials and Biostructures, 7:175-184.

Ramachandran, P. and Nagarajan, S. (2014). Quality characteristics, nutraceutical profile, and storage stability of aloe gel-papaya functional beverage blend. International Journal of Food Science, 1:1-7.
Rathore, R.; Jain, S. and Kumari, M. (2017). Scientific validation of traditional wisdom on analgesic effect of selected plant sources. Anna. of Phytomedicine., 6:107-113.

Saka, W.A.; Akhigbe, R.E.; Popoola, O.T. and Oyekunle, O.S. (2012). Changes in serum electrolytes, urea, and creatinine in Aloe vera treated rats. Journal of Young Pharmacists, 4:78-81.

Sharma, R.; Burang, G.; Kumar, S.; Sharma, Y.P. and Kumar, V. (2021). Optimization of apricot (Prunus armeniaca L.) blended Aloe vera (Aloe barbadensis M.) based low-calorie beverage functionally enriched with aonla juice (Phyllanthus emblica L.). Journal of Food Science and Technology, 1-12.

Tabak, A.G.; Herder, C.; Rathmann, W.; Brunner, E.J. and Kivimäki, M. (2012). Prediabetes: A high-risk state for diabetes development. Lancet, 379:2279-2290.

Devina Vaidya, Anuradha Pandit, Anshu Sharma, Manisha Kaushal, Harpreet Kaur Saini, Anupama Anand, Ruchi 